\title{
Hereditary inclusion body myopathy-joint contractures-ophthalmoplegia syndrome
}

INSERM

\section{Source}

INSERM. (1999). Orphanet: an online rare disease and orphan drug data base. Hereditary inclusion body myopathy-joint contractures-ophthalmoplegia syndrome. ORPHA:79091

Hereditary inclusion body myopathy type 3 is characterised by congenital joint contractures (normalizing during early childhood), external ophthalmoplegia, and proximal muscle weakness. In adult cases, the muscular weakness is progressive. 